九州大学学術情報リポジトリ

Kyushu University Institutional Repository

\title{
Synthesis of single-walled carbon nanotubes using laser-vaporized metal nanoparticle catalyst
}

Kohno, Masamichi

Department of Mechanical Engineering, Kyushu University

Kawahara, Teppe i

Department of Mechanical Engineering, Kyushu University

Tomoda, Masahiro

Department of Mechanical Engineering, Kyushu University

Takata, Yasuyuki

Department of Mechanical Engineering, Kyushu University

他

http://hdl. hand le. net/2324/25437

出版情報: Journal of Mechanical Science and Technology. 25 (1), pp.11-15, 2011-01-01. Korean Society of Mechanical Engineers

バージョン:

権利関係: (C) 2011 The Korean Society of Mechanical Engineers and Springer-Verlag Berlin He ide lberg. 


\title{
Synthesis of single-walled carbon nanotubes using laser-vaporized metal nanoparticle catalyst
}

\author{
Masamichi Kohno ${ }^{1}$, Teppei Kawahara ${ }^{1}$, Masahiro Tomoda ${ }^{1}$, Yasuyuki Takata ${ }^{1}$, \\ Shuhei Inoue ${ }^{2}$, Shinzo Suzuki ${ }^{3}$, Shigeo Maruyama ${ }^{4}$ \\ ${ }^{I}$ Department of Mechanical Engineering, Kyushu University \\ ${ }^{2}$ Department of Mechanical System Engineering, Hiroshima University \\ ${ }^{3}$ Department of Physics, Kyoto Sangyo University \\ ${ }^{4}$ Department of Mechanical Engineering, The University of Tokyo
}

\begin{abstract}
SWNTs were synthesized by laser-vaporized CCVD (catalytic chemical vapor deposition). The diameter distributions and the abundance of SWNTs synthesized at different temperatures and using different catalysts were investigated by Raman spectroscopy. Further, this technique was compared with other synthesis techniques (laser-oven and conventional-alcohol CCVD), and $\mathrm{C}_{60}$ was synthesized simultaneously as a byproduct only using the laser-oven technique. With increasing synthesis temperature, the diameter distribution shifted towards larger diameters, and the G/D ratio became larger as the synthesis temperature increased to $1000^{\circ} \mathrm{C}$. Ni, Co, and Fe played a catalytic role, though Fe was less effective under our experimental conditions. The diameter distribution of SWNTs synthesized with the Fe catalyst was shifted to smaller values compared to those synthesized with Ni or Co catalysts.
\end{abstract}

Keywords: SWNTs; Laser vaporization; CVD; Raman spectroscopy

1.1

\section{Introduction}

Since the discovery of single-wall nanotubes (SWNTs) [1], many synthesis techniques, such as the laser-oven technique [2], the arc-discharge technique [3], and various catalytic chemical vapor deposition (CCVD) techniques [4] have been developed. We have proposed a CCVD technique using alcohol as the carbon source (ACCVD), which has been shown to produce high-quality SWNTs [5] and can be performed at a significantly lower temperature compared to other CCVD techniques. Although, recently, the ACCVD technique has become increasingly popular, the mechanism for the growth of SWNTs from ethanol vapor and the effect of the metal catalyst during the formation process are not yet well understood. Nishide et al. developed laser-vaporized CCVD [6], which combines laser vaporization and ACCVD. In this technique, nanoscale catalyst particles are generated by the pulsed-laser vaporization of a metal rod, with ethanol vapor employed as the carbon source to synthesize SWNTs. Although this technique is not suitable for the mass production of SWNTs, it is appropriate for research into their growth mechanism because various parameters, such as the type of the metal catalyst, pressure, mass flow of alcohol (i.e., the carbon source), and the temperature of the electric furnace, can be controlled individually. Nishide et al. synthesized SWNTs with $\mathrm{Fe}, \mathrm{Ni}, \mathrm{Co}$, and $\mathrm{Ni} / \mathrm{Co}$ catalysts at $850^{\circ} \mathrm{C}$, and examined the influence of the synthesis temperature on the yield and diameter distribution for the Co catalyst.

The present study examines this technique in further detail by comparing the SWNTs with those synthesized by a conventional laser-oven ACCVD technique. It also examines the influence of the synthesis temperature on the yield and diameter distribution with $\mathrm{Ni}$ and $\mathrm{Fe}$ catalysts.

\section{Experiment}

Fig. 1 shows a schematic drawing of the laser-vaporized CCVD apparatus. It consists of a nanosecond pulsed Nd:YAG laser (wavelengths $1064 \mathrm{~nm}$ and $532 \mathrm{~nm}$ ), two vacuum chambers, an electric furnace with a quartz tube $(20 \mathrm{~mm}$ in diameter, $100 \mathrm{~cm}$ long) inside it, a molybdenum rod and a target rod (6 $\mathrm{mm}$ in diameter). Vacuum chambers terminate both ends of the quartz tube into which the molybdenum rod, which carries the target rod on its tip, is inserted. During the experiment, ethanol vapor (the carbon source) flows into the quartz tube at a constant pressure of 40 Torr. The quartz tube is heated to a temperature between $700{ }^{\circ} \mathrm{C}$ and $1100{ }^{\circ} \mathrm{C}$. A mixture of the fundamental and of the second harmonic of the Nd:YAG laser (with a typical beam intensity of $200 \mathrm{~mJ} / \mathrm{pulse}$ and a frequency of $10 \mathrm{~Hz}$ ) was irradiated onto the surface of the metal target rod to ablate catalyst particles. The target is attached to the tip of the rotating molybdenum rod to expose a 


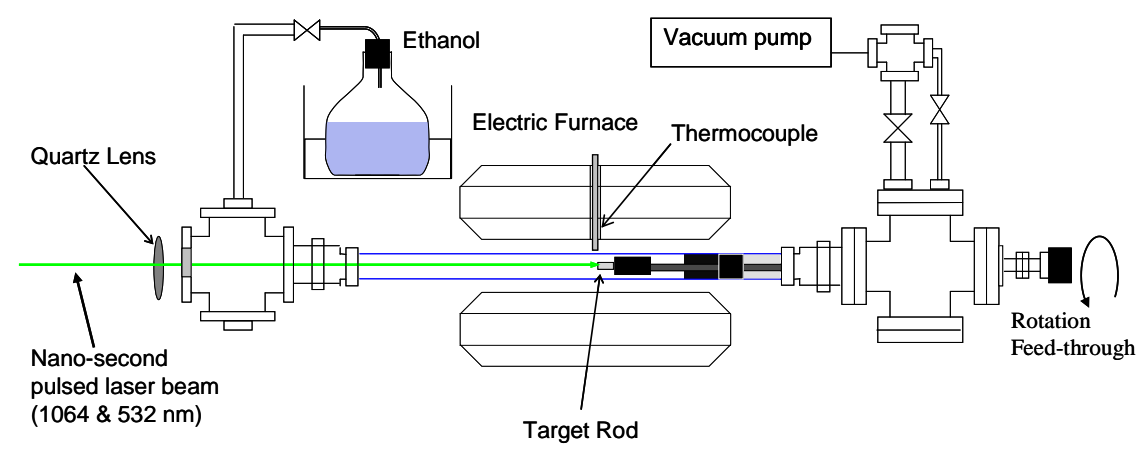

Figure 1. Schematic drawing of the laser-vaporized CCVD technique.

fresh surface of the target continuously to the beam. After 30 min of laser ablation, the resulting soot, which includes SWNTs, is deposited onto the molybdenum rod and onto the inner wall of the quartz tube (around the outlet of the electric furnace). It is then collected for characterization.

The laser-oven technique involves a similar procedure, but $\mathrm{N}_{2}$ is used as the buffer gas instead of ethanol vapor and a $\mathrm{Ni} / \mathrm{Co}(0.6 / 0.6$ at $\mathrm{wt} \%)$ carbon composite rod is attached to the tip of the molybdenum rod instead of the metal rod. The temperature of the electric furnace is between $800{ }^{\circ} \mathrm{C}$ and $1100{ }^{\circ} \mathrm{C}$ and the $\mathrm{N}_{2}$ gas is maintained at atmospheric pressure and a flow rate of $0.15 \mathrm{~L} / \mathrm{min}$. The laser-beam intensity to ablate the surface of the rod was typically $80 \mathrm{~mJ} / \mathrm{pulse}$. The ablated carbon and metal particles serve as the carbon source and catalyst, respectively, for synthesizing SWNTs. After 30 minutes of laser ablation, the soot is collected in a similar manner to the laser-vaporized CCVD technique. The diameter distribution and the yield of SWNTs are again evaluated by Raman spectroscopy (using 488, 532 and $785 \mathrm{~nm}$ excitations).

\section{Results and discussions}

\subsection{Comparison of the laser-oven and conventional alcohol CCVD techniques}

Fig. 2 shows a typical TEM image of the as-grown soot synthesized by laser-vaporized CCVD at $900{ }^{\circ} \mathrm{C}$ (Ni catalyst). As shown in the figure, many of the synthesized SWNTs form bundles. Compared to soot prepared by the conventional laseroven technique [7-8], more metal particles exist in the raw soot prepared by the present laser-vaporized CCVD. Nishide et al. reported [6] that these metal particles are coated with graphitic layers, as these do not dissolve readily in hydrochloric acid.

Fig. 3 (left panel) shows the low-frequency and (right panel) the high-frequency regions of the Raman spectra for the collected as-grown soot prepared by several synthesis techniques: (a) the laser-oven $\left(1100{ }^{\circ} \mathrm{C}\right.$, catalyst: $\left.\mathrm{Ni} / \mathrm{Co}\right)$, (b) the laser-vaporized CCVD $\left(1000{ }^{\circ} \mathrm{C}\right.$, catalyst: $\left.\mathrm{Ni}\right),(\mathrm{c})$ the

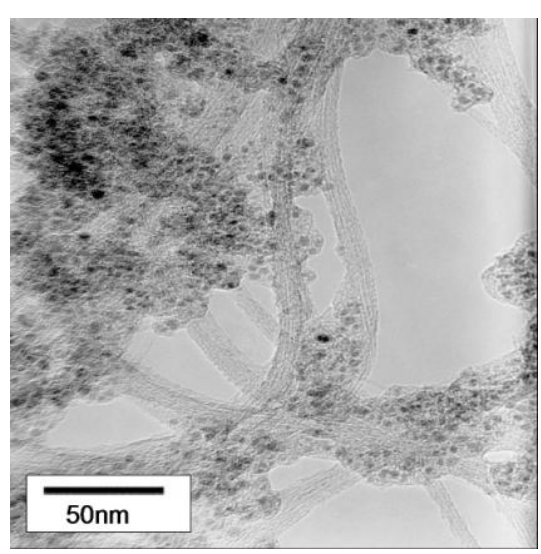

Figure 2. TEM image of SWNTs synthesized by laservaporized $\mathrm{CCVD}\left(900^{\circ} \mathrm{C}\right.$, Ni catalyst).

laser-vaporized CCVD $\left(800{ }^{\circ} \mathrm{C}\right.$, catalyst: $\left.\mathrm{Ni}\right)$, and (d) ACCVD $\left(800^{\circ} \mathrm{C}\right.$, catalyst: $\mathrm{Fe} / \mathrm{Co}$ fine particles supported on zeolite) [5]. Ethanol vapor was used as the carbon source for both the laser-vaporized CCVD and ACCVD. SWNTs were not synthesized at $1100{ }^{\circ} \mathrm{C}$ by laser-vaporized CCVD because the ethanol decomposes. In Fig. 3 (left panel), the peaks in the range from around 160 to $210 \mathrm{~cm}^{-1}$ correspond to radial breathing modes (RBM). They provide indications on the SWNT diameter distribution, based on the correlation between the diameter $d$ and the RBM Raman shift $\varpi$, used to define the scale of the diameter axis: $d / \mathrm{nm}=248 /\left(\varpi / \mathrm{cm}^{-1}\right)$ [9]. The RBM spectra for the laser-oven and the laser-vaporized CCVD at $1000{ }^{\circ} \mathrm{C}$ cover a range of around $160-210 \mathrm{~cm}^{-1}$, corresponding to the diameter distribution of $1.2-1.5 \mathrm{~nm}$. However, the RBM peak around $250 \mathrm{~cm}^{-1}$, corresponding to the diameter distribution around $1.0 \mathrm{~nm}$, was observed only with laservaporized CCVD. The RBM spectra of the laser-vaporized CCVD (at $800^{\circ} \mathrm{C}$ ) and ACCVD cover a wide range, 160$265 \mathrm{~cm}^{-1}$, corresponding to the diameter distribution of 0.9 $1.6 \mathrm{~nm}$. This result suggests that the synthesis temperature is 

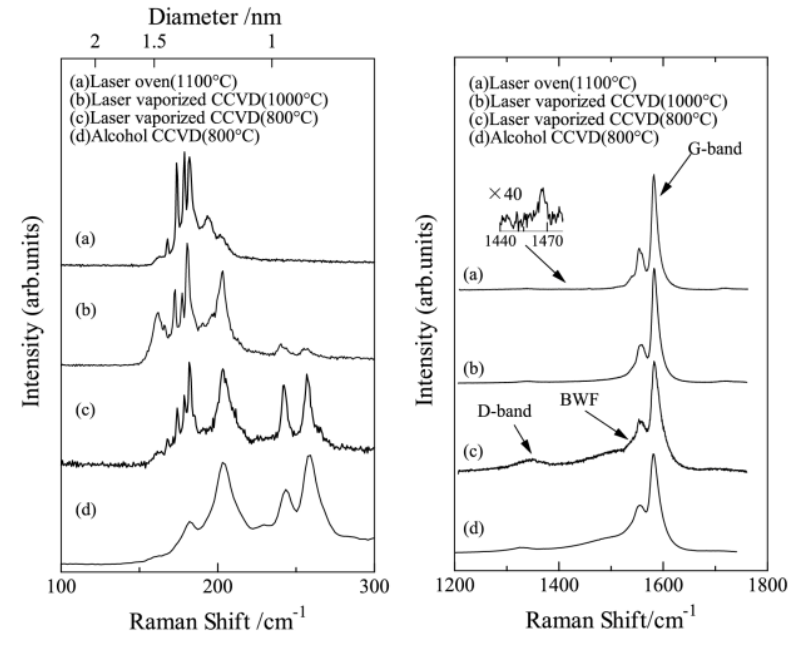

Figure 3. (Left panel) The low-frequency and (right panel) high-frequency regions of the Raman spectra of the collected as-grown soot prepared by several synthesis techniques. (a) Laser oven $\left(1100^{\circ} \mathrm{C}\right.$, catalyst: $\left.\mathrm{Ni} / \mathrm{Co}\right)$, (b) the laser-vaporized CCVD $\left(1000^{\circ} \mathrm{C}\right.$, catalyst: $\left.\mathrm{Ni}\right)$, (c) laser -vaporized CCVD $\left(800^{\circ} \mathrm{C}\right.$, catalyst: $\left.\mathrm{Ni}\right)$, (d) ACCVD $\left(800{ }^{\circ} \mathrm{C}\right.$, catalyst: $\mathrm{Fe} / \mathrm{Co}$ fine particles supported on Zeolite) [5].

the dominant factor in defining the diameter distribution and a condition (in gas phase or supported on substrate) of metal catalysts.

In Fig. 3 (right panel), high-frequency Raman peaks are observed in all cases. The G-band (a superposition of 1593 $\mathrm{cm}^{-1}$ and $1568 \mathrm{~cm}^{-1}$ ), which originates in the cylindrical graphite structure of SWNTs, is characteristic of semiconductor SWNTs [10-11]. The broad peak observed around $1550 \mathrm{~cm}^{-1}$ is the Breit-Wigner-Fano (BWF) line, and this indicates that the SWNTs are metallic [12-13]. The Dband, located around $1350 \mathrm{~cm}^{-1}$ and because of amorphous carbon or defects in the carbon network, was hardly observed for synthesis at $1000{ }^{\circ} \mathrm{C}$ but appeared weakly at $800{ }^{\circ} \mathrm{C}$. Peaks that originate in $\mathrm{C}_{60}$ were observed around $1468 \mathrm{~cm}^{-1}$ [14]only in the soot synthesized using the laser-oven technique. Thus, fullerenes seem to be synthesized simultaneously as a byproduct. Earlier studies have suggested different SWNT growth mechanisms for the laser-oven and the CCVD techniques [6]. In the context of the laser-oven technique, the "fullerene cap model" [15] proposes that carbon in fullerene cap structures is a precursor to SWNTs. It is well known that fullerenes are always synthesized as a byproduct in the laseroven technique and that the diameter distribution of SWNTs is influenced by the size distribution of the higher fullerenes [7, 15]. It is therefore conceivable that a few fullerene cap structures grow to form $\mathrm{C}_{60}$ under our experimental conditions of the laser-oven technique, and that the growth mechanism relevant for each technique results in different diameter distributions.

\subsection{Influence of metal catalyst in SWNT synthesis.}

Fig. 4 shows Raman spectra of as-grown soot prepared by the laser-vaporized CCVD technique at different temperatures $\left(800^{\circ} \mathrm{C}\right.$ and $\left.1000^{\circ} \mathrm{C}\right)$ and with different catalysts $(\mathrm{Ni}$ and $\mathrm{Fe})$. The left panel shows the low frequencies and the right panel the high frequencies. The result for $\mathrm{Ni}$ is almost the same as that of a previous study where Co was used as the catalyst [6].

With increasing synthesis temperature, the center of gravity of the peaks is shifted towards lower frequencies and the distribution becomes narrower. The RBM spectrum $(\mathrm{Ni}$, $1000{ }^{\circ} \mathrm{C}$ ) mainly covers the range 160-210 $\mathrm{cm}^{-1}$, corresponding to the diameter distribution of $1.2-1.5 \mathrm{~nm}$. Specifically, thin nanotubes with a diameter of around 0.96 or $1.02 \mathrm{~nm}$ are barely observed at $100{ }^{\circ} \mathrm{C}$ while their presence is abundant at $800{ }^{\circ} \mathrm{C}$. In the case of Fe catalyst, the RBM peaks around $240-255 \mathrm{~cm}^{-1}$ are largest at $800{ }^{\circ} \mathrm{C}$. However, at $1000{ }^{\circ} \mathrm{C}$, the peaks around $200 \mathrm{~cm}^{-1}$, corresponding to the diameter of around $1.2 \mathrm{~nm}$, become dominant. Comparing the spectra corresponding to $800{ }^{\circ} \mathrm{C}$ and $1000{ }^{\circ} \mathrm{C}$, the tendency observed for both catalysts is that the higher synthesis temperature gives a higher yield of large SWNTs. More large SWNTs are synthesized at $1000^{\circ} \mathrm{C}$ with Ni catalyst than with $\mathrm{Fe}$. It is possible that the size distributions of $\mathrm{Ni}$ and $\mathrm{Fe}$ metal particles, produced by laser ablation of the metal rod, are different, resulting in different SWNT diameter distributions. Further study, e.g., by TEM, is necessary to understand this difference.

In the right panel in Fig. 4, the BWF lines are observed clearly at $800^{\circ} \mathrm{C}$ and their intensity decreases as the synthesis temperature increases to $1000{ }^{\circ} \mathrm{C}$ for both catalysts, consistent
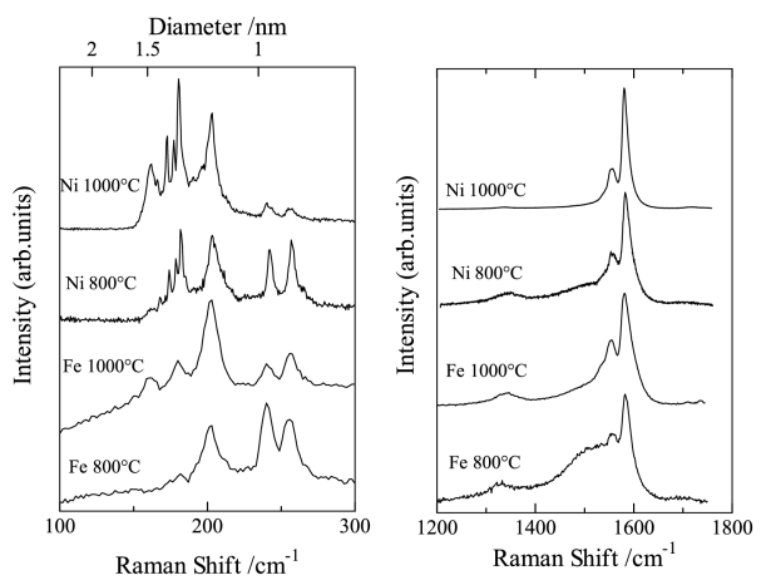

Figure 4. Raman spectra of SWNTs synthesized by laservaporized CCVD at different temperatures $\left(800{ }^{\circ} \mathrm{C}\right.$ and $1000{ }^{\circ} \mathrm{C}$ ) and with different catalysts (Ni and $\mathrm{Fe}$ ). (Left panel: the low-frequency region, right panel: the highfrequency region) 
with the result of the RBM region. The G/D ratio (the ratio between intensity of the G-band and D-band), which measures the yield of SWNTs, increases as the reaction temperature rises for both catalysts. If the BWF line dominates the G-band structure, it is difficult to use the G/D ratio as a measure of the yield. Comparing the spectra of SWNTs synthesized with $\mathrm{Ni}$ or Fe at $1000^{\circ} \mathrm{C}$, the BWF line is barely observed in the case of $\mathrm{Fe}$. It is therefore difficult to discuss the difference in yield for $\mathrm{Fe}$ and $\mathrm{Ni}$ quantitatively. However, a qualitative assessment is possible for the following reasons: (1) The D band is hardly observed in the Ni spectra but is strong with Fe; (2) the BWF line is indeed observed in the Fe case but it is not dominant. Referring to the RMB region, the semiconductor SWNTs are predominant with Fe at $1000{ }^{\circ} \mathrm{C}$. Thus, SWNTs are more abundant in a given amount of soot when $\mathrm{Ni}$ catalyst is used, while $\mathrm{Fe}$ is an ineffective catalyst.

Because Raman spectra depend on the excitation wavelength, we also used other excitation lasers with wavelengths $532 \mathrm{~nm}$ and $785 \mathrm{~nm}$. Fig. 5 shows Raman spectra of SWNTs synthesized by the laser-vaporized CCVD technique at different temperatures $\left(800{ }^{\circ} \mathrm{C}\right.$ and $\left.1000^{\circ} \mathrm{C}\right)$ and with the two catalysts ( $\mathrm{Ni}$ and $\mathrm{Fe}$ ). As shown in the figure, the diameter distribution is shifted towards larger values for $\mathrm{Ni}$ than for Fe. Though these Raman spectra do not provide the complete diameter distribution of SWNTs cannot be observed from these Raman spectra, it is clear that more large SWNTs were synthesized with Ni.

Fig. 6 shows Raman spectra for SWNTs synthesized by conventional ACCVD at different temperatures with $\mathrm{Fe}, \mathrm{Fe} / \mathrm{Ni}$ or Ni catalysts supported on zeolite for $488 \mathrm{~nm}$ excitation (left panel: low frequencies; right panel: high frequencies). Two distinct features are apparent, compared with laser-vaporized CCVD. Firstly, SWNTs are synthesized with laser-vaporized $\mathrm{Fe}$ catalyst, but not with $\mathrm{Fe}$ catalyst supported on zeolite.


Figure 5. Raman spectra of SWNTs synthesized by laservaporized CCVD at different temperatures $\left(800{ }^{\circ} \mathrm{C}\right.$ and $1000^{\circ} \mathrm{C}$ ) and with different catalysts ( $\mathrm{Ni}$ or $\mathrm{Fe}$ ), under $532 \mathrm{~nm}$ and $785 \mathrm{~nm}$ excitation.


Figure 6. Raman spectra for SWNTs synthesized by conventional ACCVD at different synthesis temperatures under $488 \mathrm{~nm}$ excitation with $\mathrm{Fe}, \mathrm{Fe} / \mathrm{Ni}$, or Ni catalyst supported on zeolite. (Left panel: the low-frequency region, right panel: the high-frequency region)

Secondly, SWNTs are synthesized by the laser-vaporized CCVD technique at $1000{ }^{\circ} \mathrm{C}$ (Ni catalyst), but not with $\mathrm{Ni}$ catalyst supported on zeolite.

It is not clear at present why SWNTs are not synthesized with Fe catalyst supported on zeolite. However, it is possible that the size of Fe catalyst supported on zeolite is not small enough to allow SWNT synthesis. It is well known that small metal particles $(1 \sim 2 \mathrm{~nm})$ are suitable for SWNT synthesis. Thus, because laser ablation of the Fe rod produces a broad range of nanoparticle sizes, SWNTs can be synthesized by laser-vaporized CCVD. Further detailed study (for example by controlling the size of Fe catalyst particles) will be needed to confirm this hypothesis.

The difference in the maximum temperature at which SWNTs are synthesized is likely to result from the different position of the catalyst in the electric furnace. A metal rod that generates catalyst particles by laser irradiation is placed at the center of the quartz tube. On the other hand, the quartz boat containing zeolite is situated on the inner wall of the tube. In our apparatus, the thermocouple measures the temperature at the outer surface of the quartz tube rather than at its center. Therefore, the actual temperature for SWNT synthesis by laser-vaporized CCVD may be lower than that measured by the thermocouple.

\section{Conclusion}

SWNTs were synthesized by laser-vaporized CCVD. We compared this technique with other synthesis techniques and investigated its dependence on the type of metal catalyst used. Compared with the laser-oven technique and conventional ACCVD, the synthesis temperature seems to be a dominant factor for determining the diameter distribution of the SWNTs but the situation (in gas phase or supported on substrate) of 
metal catalysts. However, a few differences in the diameter distribution were observed between the laser-oven technique, laser-vaporized CCVD, and ACCVD. In addition, $\mathrm{C}_{60}$ was produced as a byproduct only with the laser oven, which suggests a different precursor to the SWNTs. A tendency, observed with both $\mathrm{Ni}$ and $\mathrm{Fe}$ catalysts, is that a higher synthesis temperature yields more large SWNTs. However, at $1000{ }^{\circ} \mathrm{C}$, more large SWNTs are synthesized with Ni than with Fe. In addition, Fe appears to be an ineffective catalyst compared to $\mathrm{Ni}$.

\section{Acknowledgements}

The authors thank Dr. Peter L. Woodfield for valuable discussions. This research was partially supported by the Japanese Ministry of Education, Science, Sports and Culture, and by KAKENHI (22686024).

\section{References}

[1] S. Iijima, T. Ichihashi, Single-shell carbon nanotubes of 1-nm diameter, Nature, 363 (1993) 603605.

[2] A. Thess, R. Lee, P. Nikolaev, H. Dai, P. Petit, J. Robert, C. Xu, Y.H. Lee, S.G. Kim, A.G. Rinzler, D.T. Colbert, G.E. Scuseria, D. Tománek, J.E. Fischer, R.E. Smalley, Crystalline ropes of metallic carbon nanotubes, Science, 273 (1996) 483487.

[3] C. Journet, W.K. Maser, P. Bernier, A. Loiseau, M.L. de la Chapelle, S. Lefrant, P. Deniard, R. Lee, J.E. Fisher, Largescale production of single-walled carbon nanotubes by the electric-arc technique, Nature, 388 (1997) 756-758.

[4] J. Kong, A.M. Cassell, H.J. Dai, Chemical vapor deposition of methane for single-walled carbon nanotubes, Chem. Phys. Lett., 292 (1998) 567-574.

[5] S. Maruyama, R. Kojima, Y. Miyauchi, S. Chiashi, M. Kohno, Low-temperature synthesis of high-purity singlewalled carbon nanotubes from alcohol, Chem. Phys. Lett., 360 (2002) 229-234.

[6] D. Nishide, H. Kataura, S. Suzuki, S. Okubo, Y. Achiba, Growth of single-wall carbon nanotubes from ethanol vapor on cobalt particles produced by pulsed laser vaporization, Chem. Phys. Lett., 392 (2004) 309-313.

[7] H. Kataura, Y. Kumazawa, Y. Maniwa, Y. Ohtsuka, R. Sen, S. Suzuki, Y. Achiba, Diameter control of single-walled carbon nanotubes, Carbon, 38 (2000) 1691-1697.

[8] D. Nishide, H. Kataura, S. Suzuki, K. Tsukagoshi, A. Aoyagi, Y. Achiba, High-yield production of single-wall carbon nanotubes in nitrogen gas, Chem.phys.Lett., 372 (2003) 45-50.

[9] R. Saito, G. Dresselhaus, M.S. Dresselhaus, Trigonal warping effect of carbon nanotubes, Phys. Rev. B, 61 (2000) 29812990.

[10] A.M. Rao, E. Richter, S. Bandow, B. Chase, P.C. Eklund, K.A. Williams, S. Fang, K.R. Subbaswamy, M.
Menon, A. Thess, R.E. Smalley, G. Dresselhaus, M.S. Dresselhaus, Diameter-selective Raman scattering from vibrational modes in carbon nanotubes, Science, 275 (1997) 187-191.

[11] R. Saito, T. Takeya, T. Kimura, G. Dresselhaus, M.S. Dresselhaus, Raman intensity of single-wall carbon nanotubes, Phys. Rev. B, 57 (1998) 4145-4153.

[12] A.M. Rao, P.C. Eklund, S. Bandow, A. Thess, R.E. Smalley, Evidence for charge transfer in doped carbon nanotube bundles from Raman scattering, Nature, 388 (1997) 257-259.

[13] H. Kataura, Y. Kumazawa, Y. Maniwa, I. Umezu, S. Suzuki, Y. Ohtsuka, Y. Achiba, Optical properties of singlewall carbon nanotubes, Synth. Met., 103 (1999) 2555-2558.

[14] W. Krätschmer, L.D. Lamb, K. Fostiropoulos and D.R. Huffman, Nature, 347 (1990) 354-358.

[15] T. Ishigaki, S. Suzuki, H. Kataura, W. Krätschmer, Y. Achiba, Characterization of fullerenes and carbon nanoparticles generated with a laser-furnace technique, Appl. Phys. A, 70 (2000) 121-124.

\section{(First author)}

Masamichi Kohno is an Associate Professor of the thermofluid physics laboratory in the Department of Mechanical Engineering, Kyushu University, Japan. He received his Dr. Sci. in 1998 from Tokyo Metropolitan

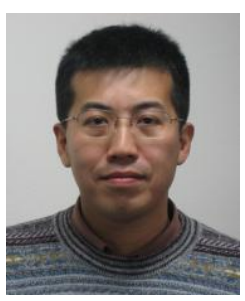
University. From 1998 to 2001, he worked as a research associate on SWNTs synthesis in the University of Tokyo, and proposed a catalytic CVD technique using alcohol as the carbon source. From 2001 to 2004, he worked in the National Institute of Advanced Industrial Science and Technology, Japan and studied laser micro/nano machining. His research is mainly focused on the area of laser ablation processes and their applications.

\section{(Corresponding author)}

Yasuyuki Takata is a professor of thermofluid physics in the Department of Mechanical Engineering, Kyushu University, Japan. He is also working as a Group Leader of the Research Center of Hydrogen Industrial Use and Storage (HYDROGENIUS) of the National Institute of Advanced Industrial Science and Technology (AIST), Japan. He received his Dr. Eng. in 1984 from Kyushu University. His research area covers phase change heat transfer, micro JT cooler, micro heat transfer devices, and thermophysical properties of hydrogen, as well as a database of thermophysical properties of fluids. 